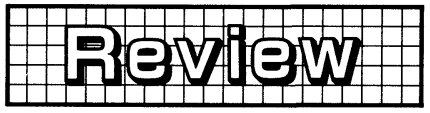

\title{
THE DESIGN OF BRACING SYSTEMS FOR PLATE GIRDER BRIDGES
}

\author{
By D. A. NETHERCOT*
}

\section{ABSTRACT}

The various functions of bracing in different forms of steel bridge construction are identified. The requirements of bracing designed to provide additional stability to potentially unstable main members is discussed and the two necessary characteristics of adequate strength and adequate stiffness identified. Particular attention is given to U-frame action, either in through girder decks or as a means of stabilising the support regions of continuous composite decks. For the latter the results of recent research suggest that bracing could often be omitted ; a method of quantifying this requirement is presented. This leads to the concept of bracing-free bridges.

\section{INTRODUCTION}

The economic design of steel bridges ${ }^{1)}$ normally requires the use of a certain amount of bracing to provide adequate stability both in the construction phase and in service. The prime function of the bracing is to limit undesirable out-of-plane deformation e. g. in a twin plate girder bridge for the main girders to achieve their required capacity it will usually be necessary to arrange that overall buckling of the whole span is prevented by reducing the effective slenderness of the girders through the use of judiciously placed intermediate bracing. Certain forms of construction naturally provide some degree of restraint to potentially unstable elements e.g. in half-through bridges the top flanges of the main girders will be supported by the webs (which may well be vertically stiffened), which in turn will be attached to the deck.

\footnotetext{
* Department of Civil and Structural Engineering, University of Sheffield, U. K.

Keywords: plate girder bridges, lateral-torsional buckling, bracing system, bracing design, through girder decks

Profile

David Nethercot graduated with First Class Honours from University College Cardiff in 1967 and was awarded a $\mathrm{Ph}$. D. from the same establishment three years later. He has some 20 years experience in research, teaching and specialist advisory work, most of it concerned with structural steelwork. His research interests lie mainly within the areas of stability and connections, particularly in the influence of connection behaviour on the performance of steel frame structures. These have resulted in 3 books and over 100 published papers. A member of BSI Committees $\mathrm{CSB} / 27$ and $\mathrm{CSB} / 36$, he has contributed to the preparation of several recent structural codes, as well as participating in the work of international technical organizations such as The European Convention for Constructional Steelwork. He is currently a Reader in Civil and Structural Engineering at the University of Sheffield.
} 
In such cases an assessment of the ability of these restraining elements to ensure the necessary stability is clearly important.

The role of bracing in steel bridge construction is not, of course, restricted to ensuring the stability of plate girders under vertical load. During erection, before the deck is in place, a set of parallel girders may well require interconnection in order to effectively resist horizontal wind loads. Box girders, if of the open top type, must have their webs properly braced until closure by placement of the deck provides their torsional and distortional stiffness. Apart from the main girders, the towers of suspension or cable-stayed bridges, columns supporting cross-heads and compression members in trusses, may well require some degree of bracing. When considering bracing it is important to be sure that the arrangement provided does not alter the designer's original concept of load transfer through the structure e. g. when selecting an arrangement to tie together a series of beams the desirability or otherwise of using the bracing to distribute load transversely between the beams needs to be borne in mind.

It is the purpose of this paper to discuss the function of bracing with particular reference to the prevention of the overall instability of longitudinal bridge beams. In this context a distinction is drawn between the requirements when compact sections are used-for which bracing design may be based upon the classical theory of lateral instability-and those necessary for girders whose web flexibility introduces the possibility of a distortional mode of buckling. Attention is also given to the concept of a reduced use of bracing through a better appreciation of those forms of restraint inherent in certain types of bridge construction.

\section{LATERAL-TORSIONAL BUCKLING}

Fig. 1 illustrates the classical lateral-torsional buckling mode for a simply supported beam of non-deformable cross-section. Two components of out-of-plane deformation are involved: lateral deflection $u$ and twist $\phi$. Thus for gravity loading the top (compression) flange will deflect further than the bottom flange. Methods of determining the critical value of this applied load for a wide variety of load arrangements, assuming elastic bebaviour, have been extensively developed ${ }^{2}$ and the results collected together in useful summaries ${ }^{3)}$.

For real beams buckling will be influenced by the presence of "imperfections", the most important of which are initial deformations and residual stresses. Thus design codes typically) contain a relationship between an estimated "true" lateral-torsional buckling strength and a set of parameters describing the beam, in which adjustments to the elastic critical values have been made. Frequently the basis for such a relationship will be an appraisal of the appropriate test data ${ }^{5)}$, although modern numerical methods ${ }^{6}$ are now capable of providing solutions for the ultimate strength problem in which rigorous allowance may be made for all important effects e. g. loss of bending, torsional and warping stiffnesses due to spread of yield as influenced by any pattern of residual stress, initial bow and initial twist, variation of material

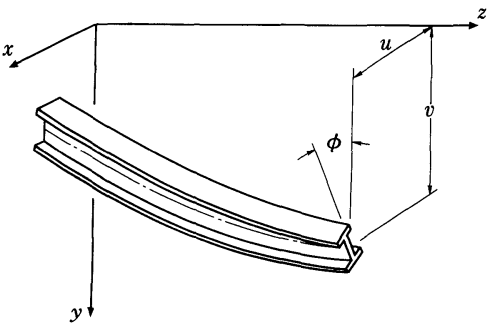

Fig. 1 Deformations associated with lateral-torsional buckling.

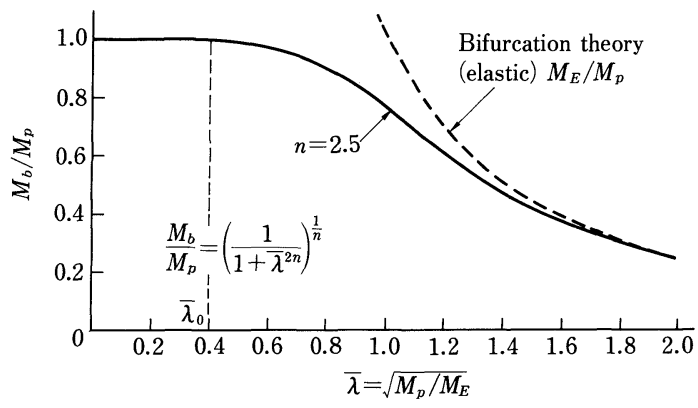

Fig. 2 Typical relationship between buckling resistance $M_{b}$ and beam slenderness ${ }^{9)}$. 
properties in different parts of the cross-section, second order coupling of flexural and torsional effects etc.

As an example, Fig. 2 gives the relationship between resistance moment $M_{b}$-expressed as a fraction of plastic moment capacity $M_{p}$-and the beam slenderness parameter $\bar{\lambda}$-recommended by the $\operatorname{ECCS}^{7}$. This style of presentation has formed the basis for several recent national codes e.g. ref. 3), even when different types of $M_{b}, \bar{\lambda}$ relationship have been used.

Clearly for values of $\bar{\lambda}$ in excess of $\bar{\lambda}_{0}$ in Fig. 2, $M_{b}$ will be less than $M_{p}$ and the full moment capacity of the cross-section cannot be used. Restricting unbraced lengths so that $\bar{\lambda} \leqq \bar{\lambda}_{0}$, through the use of an effective lateral bracing system, is one means of fully utilising the beam's moment capacity.

It should also be noted that design curves of the type shown as Fig. 2 are normally based on the assumption $^{7}$ that the beam segment under consideration will be a single span subject to uniform moment. In principle, the beam slenderness parameter $\bar{\lambda}$ depends directly on the elastic critical moment $M_{E}$ for the actual conditions of loading and restraint, as given by $\bar{\lambda}=\sqrt{M_{p} / M_{E}}$. Thus if $M_{E}$ for the actual conditions is known, reduced values of $\bar{\lambda}$ leading to higher values of $M_{b}$ will result-assuming the actual conditions to be more favourable in terms of lateral stability.

\section{BRACING}

Since lateral-torsional buckling involves two types of deformation-lateral deflection and twist-bracing may be designed to resist either or both actions and it is customary to treat the action of bracing as being equivalent to that of deflectional or rotational springs as illustrated in Figs. 3 (a), (b). For both types the spring may act at any elevation on the cross-section. In the case of deflectional restraint, its effectiveness will normally increase with height of attachment, since it will be further from the axis about which the beam twists on buckling. However, if buckling occurs in a distortional mode, then much more complex buckled shapes are possible ${ }^{8)}$, and the restraining effect/buckled shape interaction therefore needs careful modelling.

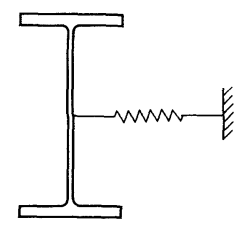

(a) Resisting lateral deflection

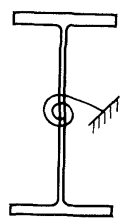

(b) Resisting twist

Fig. 3 Bracing action.

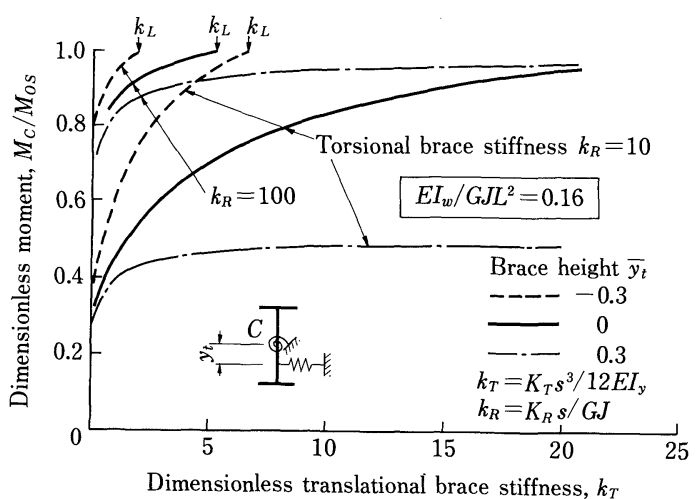

Fig. 4 Typical relationships between enhanced elastic critical moment $M_{E}$ and bracing stiffness $k^{9)}$.

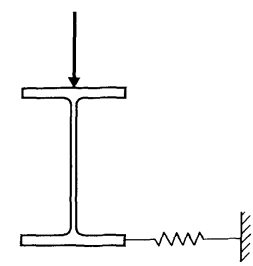

Fig. 5 Potentially ineffective arrangement of bracing and applied loading. 
Using the basic bifurcation theory of non-distortional buckling, numerous solutions for the relationship between enhanced elastic critical load and bracing stiffness for a wide variety of loading and bracing arrangements have been obtained ${ }^{9}$. These generally exhibit the characteristics of Fig. 4, the most important of which is the presence (or otherwise) of a limiting value of restraint stiffness $k_{L}$ beyond which no further increase in buckling load occurs. Fig. 4 contains results for two different values of torsional bracing stiffness $k_{R}$ and three different levels of attachment of translational bracing, as defined by $\bar{y}_{t}$, of stiffness $k_{r}$. All results are shown as ratios of the enhanced elastic critical load with the bracing in place $M_{c}$ to that of the equivalent unbraced beam $M_{o s}{ }^{9}$. Values of $\bar{y}_{t}=0.3$ and -0.3 correspond approximately to top flange and bottom flange attachment respectively of the translational bracing. This is due to a change in the buckled shape, with the restraint no longer being required to deform. Clearly designing bracing to just achieve $k_{L}$ would appear to represent the optimum condition. In certain circumstances-usually for lateral bracing close to the torsional axis and transverse loading acting above this level as shown in Fig. 5-no change of mode will occur no matter how large $k$ is made i. e. $k_{L}$ does not exist. This is due to the inability of the bracing to force the beam to buckle in a higher mode. When multiple restraints are used the situation is qualitatively similar, although more than one mode change will occur with increasing restraint stiffness before buckling between restraints finally occurs at $k_{L}$. When restraints are sufficiently stiff to force interbrace buckling they are said to be providing "complete support"

Examination of ref.9) and other more recent bracing stiffness studies ${ }^{10)}$ shows that the value of $k_{L}$ will depend upon the interaction of :

bracing type lateral, torsional or combined

beam geometry- section and slenderness

beam load type-moment gradient, distributed transverse load etc.

bracing elevation_- point of attachment to cross-section

load elevation in the case of transverse loads the level of application relative to the beam's axis.

Providing the braces function as complete supports, the solutions for enhanced elastic critical loads of ref. 2) may be employed.

Bracing studies based on the use of bifurcation theory cannot provide any information on the forces developed in the bracing9) since the buckling deformations are, by definition, indeterminate. Initial deformations must be included in the analysis so as to convert it into a more complex load-deflection problem. Using an ingenious simplification, in which a hinge was assumed at the braced point $(\mathbf{s})$, Winter ${ }^{11)}$

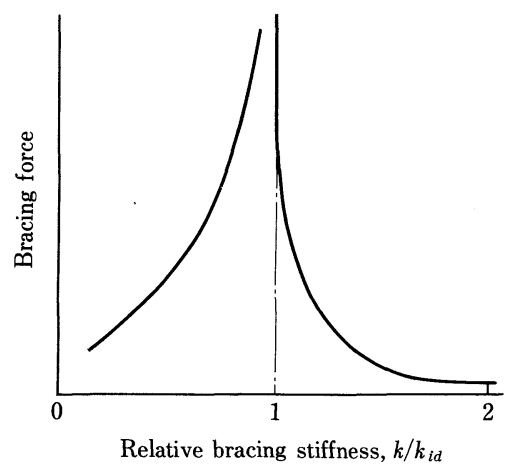

Fig. 6 Indicative relationship between bracing force and bracing stiffness.

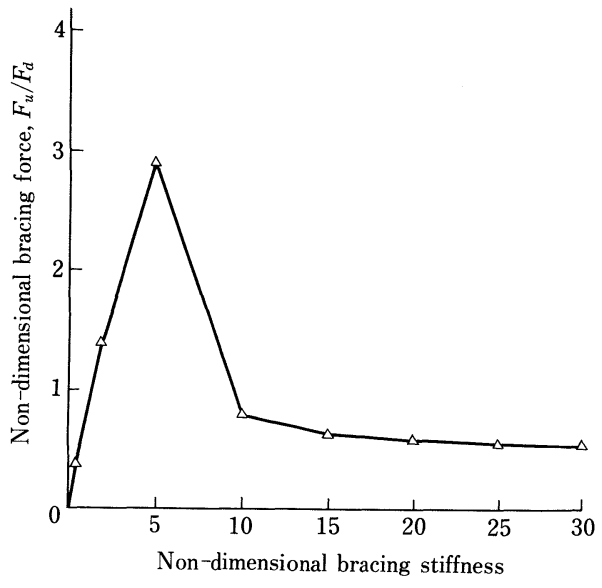

Fig. 7 Bracing force versus bracing stiffness relationship for translational bracing to top flange and uniform load on top flange. 


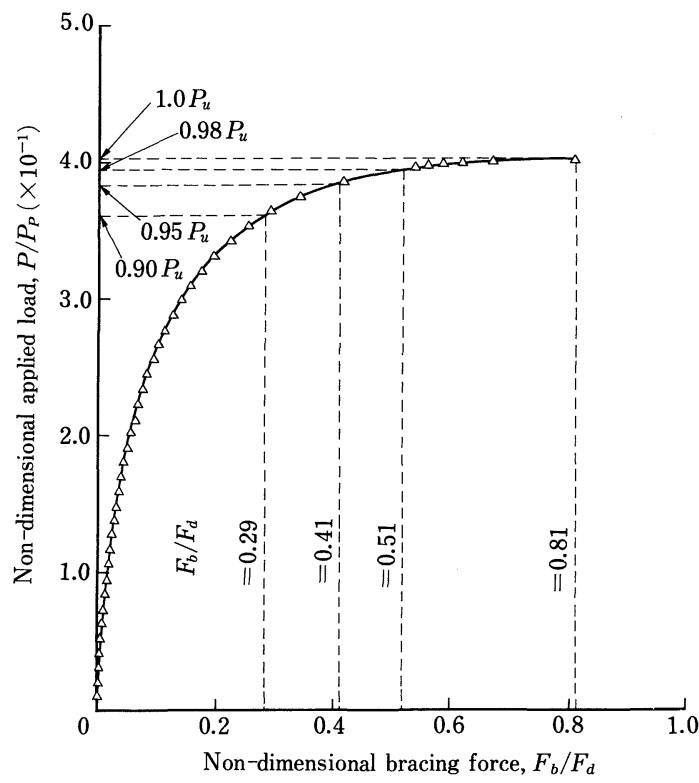

Fig. 8 Build-up of bracing force, top flange bracing and top flange uniform loading $k / 48 E I_{y} L^{3}=1.0$.

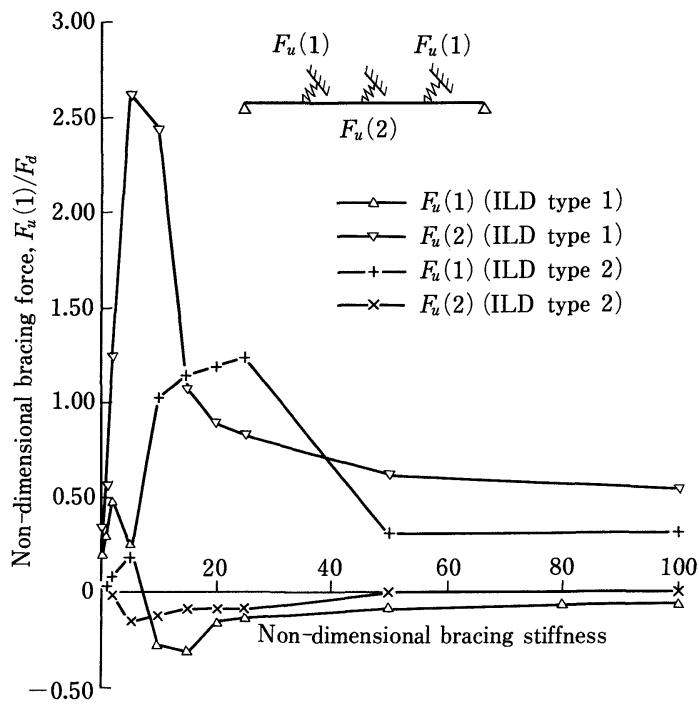

Fig. 9 Bracing force distribution for multiple bracing systems.

developed an approximate relationship between bracing force $F_{\text {req, }}$, bracing stiffness $k_{\text {act }}$, initial column out-of-straightness $\delta_{0}$ and maximum permitted column deflection $\delta$ of the form :

$$
\begin{aligned}
& F_{\text {req }}=k_{\text {act }} \delta \cdots \cdots \cdots \\
& k_{\text {act }}=k_{i d}\left(\delta_{0} / \delta+1\right)
\end{aligned}
$$

in which $k_{i d}$ refers to the value of $k$ obtained from the equivalent bifurcation problem.

Equation (2) shows clearly that the imperfect member requires a larger bracing stiffness than the perfect member if the bracing is to function as 'complete' i. e. cause buckling in two half waves. Moreover, the magnitude of this increase depends directly on the value selected for $\delta_{0}$ and $\delta$. Fig. 6 illustrates how the required bracing force reduces sharply as $k_{\text {act }}$ is increased above $k_{i d}$, or from equation (2) since $\delta_{0}$ will normally be specified as a tolerance limit as $\delta_{0}$ is reduced. Thus for bracing force requirements to be kept within reasonable limits, bracing stiffness should significantly exceed the theoretical limiting value;the figure of a least twice is often used.

Recent numerical studies ${ }^{12)}$, using a rigorous ultimate strength form of analysis ${ }^{6}$, which incorporates all of the features present in real beams discussed in section 2, have confirmed the general trends observed by Winter for several specific examples of beams. For instance, Fig. 7 shows how for a uniformly loaded beam provided with a single central restraint at the level of its top flange the bracing force-bracing stiffness relationship is similar to that of Fig. 6 . In Fig. $7 F_{u}$ is the direct force in the bracing at beam maximum load and $F_{d}$ is 1 per cent of the squash load of the beam's flange i. e. $0.01 B T \sigma_{y}$. Of most significance is the fact that once the bracing stiffness $k_{\text {act }}$ exceeds approximately twice the ideal value $k_{i d}$, then bracing forces fall to values of less than 1 per cent of the axial load in the beam's compression flange.

However, because the build-up of force in the bracing is nonlinear-since it depends directly on the nonlinear growth of buckling type deformations with increasing applied load-significantly lower bracing strengths would be required if beam design load levels were reduced. This point is illustrated in Fig. 8, which shows for one particular combination of problem variables how reducing the beam load by 10 per cent from the maximum attainable would reduce the bracing force requirement $F_{b}$ to approximately one third. At higher levels of bracing stiffness the bracing force has been found to be rather less sensitive to changes in beam load level ${ }^{12)}$, due to the reduced size of the buckling type deformations. 
Both qualitatively and quantitatively similar results have been obtained for several examples of multiple restraints as well as for bracing designed to resist twisting rather than lateral deflection ${ }^{12)}$. A particularly interesting finding in the case of multiple restraints has been the tendancy for much of the total bracing requirement to be concentrated in only some, perhaps only one, of the restraints i. e. bracing forces are not distributed equally between braces. The exact distribution depends quite significantly upon the pattern of initial deflections (ILD) present in the beam as illustrated in Fig. 9, although the total bracing force requirement appears to be relatively insensitive to the exact form of initial deformation.

\section{BRACING DESIGN}

From the discussion of the previous section it is clear that properly designed bracing must satisfy two requirements :

(1) Sufficient strength to resist the forces induced as a result of limiting the deformations of the main member (s).

(2) Sufficient stiffness to modify the buckled shape of the main member thereby increasing its load-carrying capacity.

In practice when using discrete braces it is usual in the case of the second condition to aim to provide bracing that functions as 'complete support' i. e. acts as if it were rigid. Moreover, Fig. 6 shows quite clearly that the two requirements are linked i. e. bracing strength depends upon bracing stiffness. It is therefore surprising to find that many design guides, specifications etc., pay little regard to the bracing stiffness question, providing information only on bracing forces. Admittedly it is difficult to provide simple, economic, comprehensive guidance on bracing stiffness as the requirements depend so much on the exact arrangement under consideration. Nonetheless failure to provide at least a qualitative note on the need to consider the point may well mean that bracing systems which are incapable of providing real assistance to the main members appear to be satisfactory.

\section{THROUGH GIRDER DECKS}

Fig. 10 illustrates the half through girder arrangement ${ }^{1)}$ in which the deck is located somewhere between the lower flanges of a pair of plate girders, with no interconnection at the level of the upper flanges. The full through arrangement of Fig. 11 seems nowadays ${ }^{1)}$ to be restricted to footbridges for which the walkway needs to be enclosed. For a simply supported span the top (compression) flanges of the main girders are clearly unsupported in the horizontal direction ; their stability must therefore be provided by support from the deck acting through the girder webs and/or vertical web stiffeners.

The traditional approach to this subject is via the so-called U-frame device illustrated in Fig. 12 in which the flexibility of the frame available to support the top flanges is assessed with the instability of these flanges being treated as the buckling of an elastically supported column as illustrated in Fig. 13. The stiffness of the supporting frame is normally assessed by straightforward elastic analysis using notional

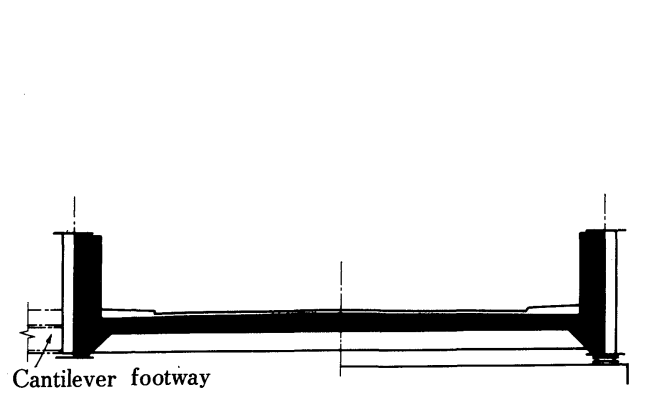

Fig. 10 Half through girder bridge.

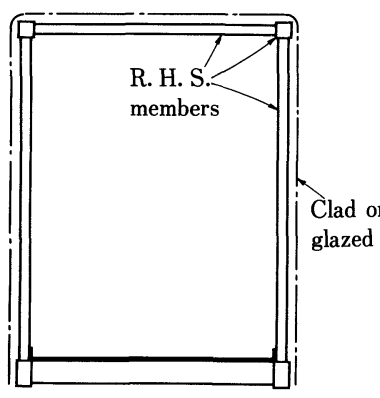

Fig. 11 Through girder bridge.

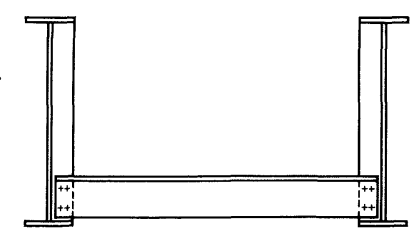

Fig. 12 Restraint of compression flange by U-frames. 
horizontal forces acting on the top flanges, possibly taking some account of flexibility in the connections.

Knowing the stiffness of the support $1 / \delta$, the elastic critical load for the compression flange buckling plane is ${ }^{12)}$ :

$$
P_{c r}=\pi^{2} E I / L_{E}^{2} \text {. }
$$

in which $L_{E}=$ the effective length of the strut.

For an elastically supported strut buckling in a single half wave the elastic critical load is :

$$
P_{c r}=\left(\pi^{2} E I / L^{2}\right)+\left(L^{2} / \pi^{2} \delta\right)
$$

for which the minimum value obtained by setting $d P_{c r} / d L$ to zero is obtained when

$$
L=\pi(E I \delta)^{0.25}
$$

substituting in Eq. (3) gives :

$$
P_{c r}=2(E I \delta)^{0.5}
$$

or

$$
L_{E}=(\pi / \sqrt{2})(E I \delta)^{0.25}
$$

This expression is the basis for the rule in BS 5400

: Part $3^{4)}$. Although more accurate analyses are available ${ }^{13)}$, these have not been distilled into a

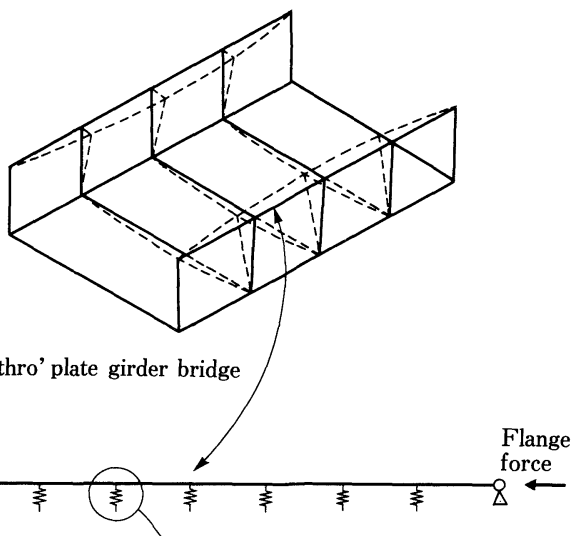

Top flange represented by a strut with elastic support

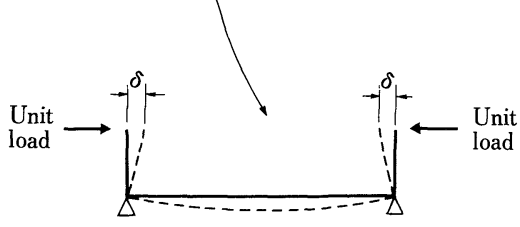

U-Frame elastic support stiffness

Fig. 13 Representation of U-Frame action ${ }^{17)}$.

form suitable for use in design.

Strictly speaking the results of Eq. (7) should form the input to a strut design curve. However, in ref. 4) the beam lateral-torsional buckling curves are used with some compensating manipulations ${ }^{14)}$ to arrive at satisfactory results. When used in ref. 4), Eq. (7) is conservatively presented as

$$
L_{E}=2.5 K_{3}(E I \delta)^{0.25} \text {. }
$$

the factor $K_{3}$ being taken as less than unity when any rotational restraint about the vertical axis is provided by the end frames. On the other hand for end frames of insufficient stiffness to prevent lateral deflection of the flange as shown in Fig. 14, using the work of Hetenyi ${ }^{15)}$ would give $\pi$ in place of $(\pi / \sqrt{2})$ in Eq. (7).

Bracing forces will be developed in the web stiffeners forming part of a U-frame due to :

1) $F_{u}$ due to magnification of the initial deformation $u_{0}$ (taken as $L_{E} / 667$ in ref. 4) which is approximately equal to the true $\left.L_{E} / 1000\right)$ by the factor $P /\left(P_{c r}-P\right)$, subject to the upper limit corresponding to interframe buckling.

2) $F_{c}$ due to rotation of the ends of the cross-beams $\theta$ leading in ref. 4) to a shear force equal to $3 E I_{1} \theta$ $/ d_{2}^{2}$, in which $I_{1}$ is the second moment of area of the vertical member (stiffener plus web plate) shown in Fig. 15.

This second contribution is conservative because :

i) It suggests that $\theta$ be taken as the simply supported crossbeam rotation $\theta_{0}$.

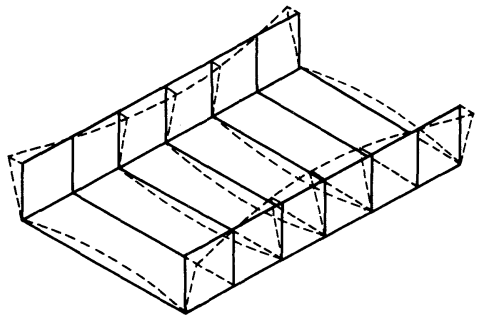

Fig. 14 Buckling mode with flexible end frames ${ }^{17)}$.

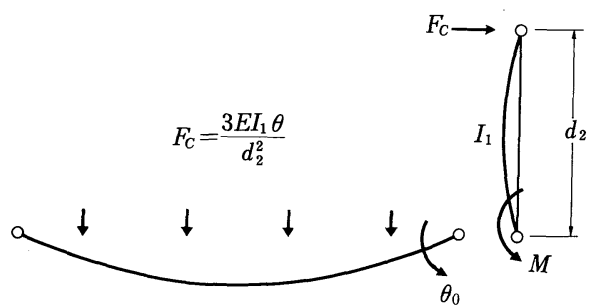

Fig. 15 Forces on U-frames ${ }^{17)}$ 
ii) It assumes bending over the full stiffener depth, including the depth of the crossbeam joint.

iii) It assumes all neighbouring U-frames are unloaded.

Alternative approaches ${ }^{16)}$ have therefore been proposed by certain UK bridge authorities which give $F_{c}=\frac{\theta_{0} / d_{2}}{d_{1} / 3 E I_{1}+B / 4 E I_{2}+f}$

in which $I_{2}=$ second moment of area of the cross-member

and $f=$ flexibility of the joint between the cross-member and the verticals.

or

$$
\begin{aligned}
& F_{c}=\frac{\theta_{0} d_{2}}{\delta+4 L_{u}^{3} / 15 E I_{c}} \\
& \delta=\text { transverse flexibility of the top of the U-frame, as used in Eq. (3) } \\
& I_{c} \text { relates to the compression flange. }
\end{aligned}
$$

An interesting case study applying the rules of ref.4) to an existing railway bridge in Australia has recently been published ${ }^{17)}$. Direct use of ref.4) suggested that the U-frames comprising the deck acting with the vertical stiffeners attached to the girder webs, did not provide sufficient stiffness to justify the value of $L_{E}$ used in the original design. Accordingly, a more refined three-dimensional finite element analysis in which the bridge was modelled as a combination of plate and beam elements was conducted to assess both the elastic buckling load of the girders and the elastic stress levels due to amplification of the measured initial lack of straightness. It is of interest that measurements conducted on several similar bridges led to the rather low figure of $L / 2000$ as being typical for the as-built values. The results of the finite element study gave an elastic critical load some 6.5 times the design load, as well as confirming that stresses would remain essentially elastic at the design load level. It would clearly be of interest if such studies could be repeated for other bridge geometries to see whether the design provisions of ref. 4) are generally too onerous.

\section{COMPOSITE DECKS}

Bracing is provided between the main steel members in continuous composite bridges for one or more of three reasons:

i) To stabilise the bare steel beams during erection both in the hogging and sagging moment regions. This is invariably necessary and the bracing must be positioned and designed to ensure the structure can safely accommodate lateral wind forces and also construction loads during casting of the concrete slab.

ii) In the completed bridge to provide stability to the compression flange in hogging moment regions. At present this is always required unless the webs of the main girders are made so stocky as to be uneconomical.

iii) To aid in the distribution of live loads between main girders in the completed bridge.

Some typical bracing systems are shown in Fig. 16. All are suitable for the purposes of (i) and (ii) above, but only the $\mathrm{K}$-bracing system is effective in providing transverse distribution of live loads. Use of bracing for this purpose implies that fatigue must be considered because stresses in the bracing system are

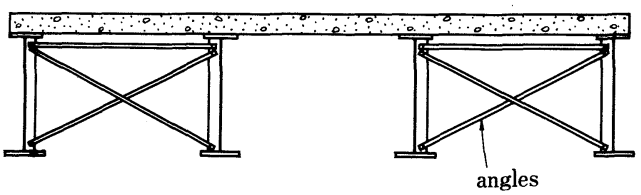

(a) Paired criss-cross

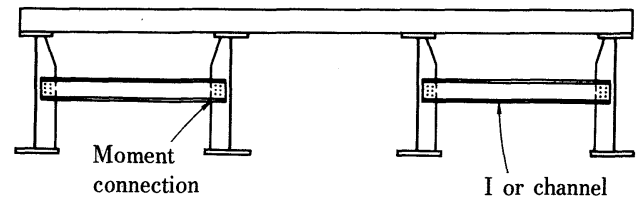

(b) Paired lateral bracing

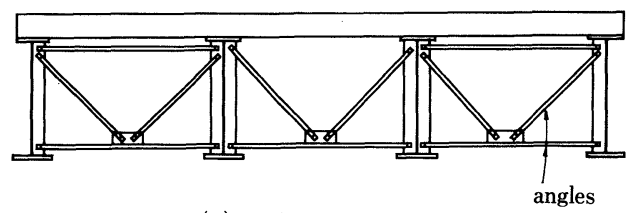

(c) K-bracing

Fig. 16 Bracing systems. 


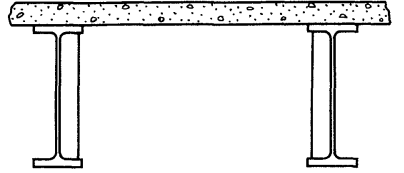

Fig. 17 Effective inverted U-frame comprising deck and web stiffeners.

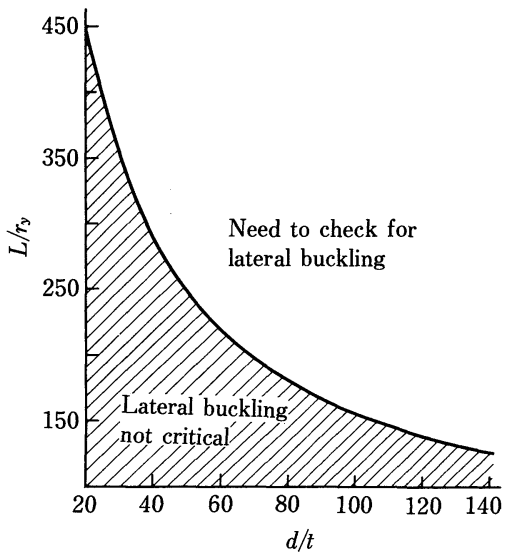

Fig. 19 Design curve for checking girder stability in hogging moment regions of continuous composite bridges ${ }^{21)}$.

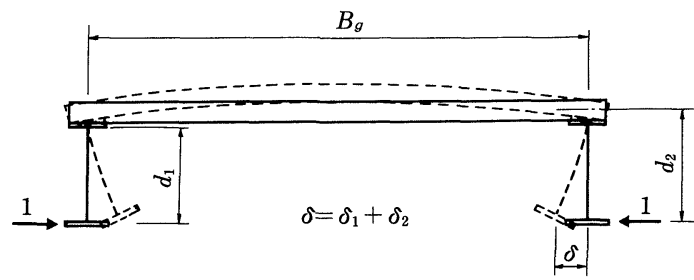

$\delta_{1}=d_{1}^{3} / 3 E I_{1}=$ deformation due to bending in web $\delta_{2}=B_{g} d_{2}^{2} / 2 E I_{2}=$ deformation due to flexure of concrete slab

(a) Two main girders

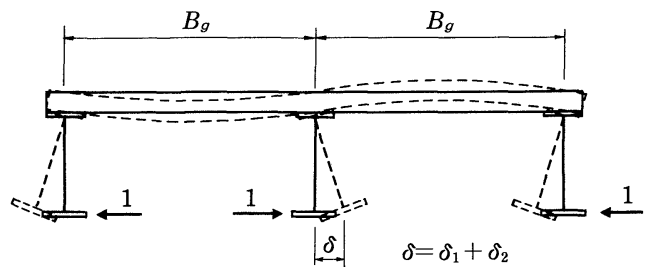

$\delta_{1}=d_{1}^{3} / 3 E I_{1}$ as above

$\delta_{2}=B_{g} d_{2}^{2} / 3 E I_{2}=$ deformation due to flexure of concrete slab

(b) Three main girders

Fig. 18 Flexibility of U-frames.

mainly induced by live loads. Consequently, it may be advisable to avoid the use of such arrangements unless careful attention has been given to the detailing of the connections and to adopt systems like the type (i) and (ii) which are fairly ineffective in transverse load distribution. These types are also less susceptible to secondary stresses due to flexure of the concrete slab under local wheel loads being transmitted to the steelwork by the "rigid" shear connection. In the mid-span regions, erection bracing can be removed once the slab has hardened sufficiently but it is often left in place because of the difficulties of working under a completed slab (for the same reason and for reasons of economy, increasing use is being made of permanent formwork). There is also a conflict of responsibility over bracing design ; should the Engineer only specify the permanent bracing requirement and place the onus for design and provision of erection bracing on the steelwork fabricator?

It is clearly advantageous for economic and contractual reasons to minimise the use of bracing. Elimination of secondary structural effects would also simplify bridge analysis. Therefore before any of the forms of bracing illustrated in Fig. 16 are employed, it is necessary to establish whether the bracing is actually required. Especially in the completed state, when full loads must be supported, the main girders will receive a significant measure of assistance from the remainder of the structure. Assessment of their stability as isolated members laterally supported merely at the bearings is thus likely to be extremely conservative.

One method of including the restraining action of the slab is to treat the support region, where the lower flange is in compression, using a modified U-frame approach. Fig. 17 illustrates an effective U-frame comprising the deck and the web stiffeners;such a method is included in ref. 4). U-frames are assumed to occur at each stiffener position with an effective section for each vertical member composed of the stiffener plus a width of web up to 16 times the web thickness on each side. The cross-member is assumed to consist of a width of slab equal to the lesser of $B_{g} / 8$ or $L_{u} / 2$, where $L_{u}$ is the distance between stiffeners. The stiffness of the vertical members in the U-frame may now be such that it is no longer acceptable to neglect the contribution of joint flexibility and an additional component must be considered in the determination of 
the deflection $\delta$. Calculations for a typical arrangement ${ }^{14)}$ suggest that this component will be extremely small in comparison with the other terms but might become significant if very large stiffeners were used. The bottom flange is again idealised as a strut on a continuous elastic foundation with each isolated elastic restraint (of modulus $1 / \delta$ ) "smoothed" into an equivalent continuous restraint of modulus $1 / L_{u} \delta$.

When no vertical stiffeners are present the girder webs act as the verticals of the U-frames. Each series of U-frames is taken as being of unit length longitudinally and a measure of the stiffness of the lateral restraint is provided by calculating the lateral deflection $\delta$ at the centroid of the compression flange under consideration due to a unit horizontal force acting at this level. Co-existent forces should be applied at the centroids of the other flanges in the system in such a direction as to produce the maximum value of $\delta$. This concept is illustrated in Fig. 18 for decks comprising two or three main girders where the expressions for $\delta$ given in ref. 4) are reproduced. Two components are included : one due to bending of the web as an isolated cantilever and one due to flexure of the concrete slab. Calculations for decks of typical proportions ${ }^{14)}$, show that the first of these will be dominant, even in girders with shallow stocky webs. This approach assumes that the shear connection froms a rigid joint ${ }^{18)}$ at each corner of the U-frame whereas in practice, as in all structural joints, some degree of flexibility will be present. The contribution of rotation at the shear connection to the lateral deflection $\delta$ has been assessed ${ }^{14)}$ using a simplified approach from which it would appear to be negligible in comparison with the other components.

An appraisal of the suitability of the above approach has been conducted ${ }^{14)}$, form which it is clear that the value of $L_{E}$ obtained is conservative on three counts:

i) It neglects the effect of moment gradient and assumes that the strut is uniformly stressed along its length (uniform moment condition).

ii) The torsional stiffness of the bottom flange is neglected.

iii) In order for lateral deflection of the bottom flange to occur near internal supports it is necessary that the web bends in the horizontal direction as well as in the vertical direction. This additional restraint has the effect of increasing the modulus of the elastic foundation and causing it to vary from a maximum at the support to a value close to that obtained in the above analysis at some distance along the span. Therefore some reduction in the effective length of the idealised strut would be expected.

The measure of conservatism introduced by neglect of the above items is difficult to ascertain precisely but an indication has been obtained by working through a typical example. This incorporates girders with a stocky, shallow web which will provide high resistance to lateral buckling and is "compact" in accordance with the definition of ref.4). When analysed by the above method the moment capacity was obtained as 0. $6 M_{p}$. This compares with strong empirical evidence to suggest that "compact" composite girders may comfortably attain their full plastic moment capacity without any significant lateral deformation of the lower flange. Indeed, recent experimental work in Japan ${ }^{20)}$ has shown that the full in-plane beam strength may be attained for values of $L / r_{y}$ in excess of 600 .

The need for stability bracing in the final condition in the support regions of continuous composite bridges may be assessed on a more realistic basis using the results of a recent numerical study ${ }^{21)}$. This found that direct application of the methods of ref. 4), which were, of course, not originally specifically intended for this form of construction, can be extremely conservative, far higher load carrying capacities being predicted by the analysis that allows for the three factors identified above than are given by the code approach for bare steel sections. Thus much larger laterally unsupported lengths are possible. As a result of this work the chart of Fig. 19 may be used to determine immediately whether the full moment capacity of the girder is available. The basis is the design approach of ref. 4) but with the effective beam slenderness determined so as to reflect the three beneficial effects referred to above. Inspection of Fig. 19 clearly shows that the majority of practical arrangements will not require lateral bracing in the support region.

It therefore follows that for many continuous composite bridges of short and medium span permanent 
bracing in the hogging moment regions will not be needed. Further research on temporary stability requirements could thus lead to bridges that are entirely free of conventional bracing systems. One possibility would be to provide this temporary stability via the use of profiled steel decking acting as permanent formwork for the slab, thereby enabling all work to be conducted on top of the steel girders. Preliminary studies ${ }^{15}$ ) using a method developed for decking and beams of the proportions typically found in buildings $\mathrm{s}^{21)}$ suggests that the decking alone will not provide sufficient shear stiffness to fully restrain large bridge girders. One possibility would be to augment this action with small joists placed at suitable intervals along the span in the troughs of the deck and eventually cast into the slab. By using suitable bolted connections through the deck into the top flange of the main girders the torsional restraint from the joists could be mobilised. Such a system might well prove to be very economical in terms of fabrication and erection time compared with traditional bracing arrangements.

\section{CONCLUSIONS}

The fundamental requirements of adequate stiffness and adequate strength for any bracing system have been identified and have been shown to be inter-related. For many plate girder bridge problems an approach based on $U$-frame action may be an appropriate approximate technique for assessing the effectiveness of both the inherent and specifically provided bracing arrangements. However, more rigorous treatments of specific problems suggest that greatest stability will often be present, leading to a reduced requirement for bracing. In the case of continuous composite decks a simple design chart is provided.

\section{ACKNOWLEDGEMENTS}

This paper is an extended version of that given by the author under the title "Design : Bracings" to the ECCS/BCSA International Symposium on Steel Bridges held in February 1988 in London. The author is grateful to the British Constructional Steelwork Association (from whom the symposium proceedings may be obtained) for permission to reproduce material from the original paper. He also acknowledges the contributions of Dr. G. Weston and Dr. Y. C. Wang to the technical content of parts of the paper.

\section{REFERENCES}

1) Tordoff, D. : Steel Bridges: The Practical Aspects of Fabrication which Influence Efficient Design, BCSA Publication No. 15/85, March 1985.

2) Nethercot, D. A. : Lateral Buckling, Second Regional Colloquium on Stability of Steel Structures, Hungary, Final Report, pp. 99-117, 1986.

3) Dux, P. F. and Kitipornchai, S. : Elastic Buckling Strength of Braced Beams, Journal of the Australian Institute of Steel Construction, Vol. 20, No. 1, May 1987.

4) BS $5400:$ Part 3, Design of Steel Bridges, BSI, London, 1982.

5) Fukumoto, Y. and Itoh, Y. : Lateral-Torsional Buckling Strength of Steel Beams from Test Data, Proceedings JSCE, No. 341, Jan. 1984.

6) El Khenfas, M. A. and Nethercot, D. A. : Ultimate Strength Analysis of Steel Beam-Columns subjected to Biaxial Bending and Torsion, Proceedings Applied Solid Mechanics-2, pp. 381-399, April 1987 (extended version to be published in Res Mechanica, 1989).

7) European Convention for Constructional Steelwork : European Recommendations for Steel Construction, The Construction Press, London, 1981.

8) Bradford, M. A. : Buckling of Elastically Restrained Beams with Web Distortions, Thin Walled Structures, Vol.6, pp. 287-304, 1988 .

9) Trahair, N.S. and Nethercot, D. A. : Bracing Requirements in Thin-Walled Structures, Developments in Thin-Walled Structures-2, ed. J. Rhodes and A. C. Walker, Applied Science Publishers, pp. 93-130, 1983.

10) Tong Gen-Shu and Chen Shao-Fan : Buckling of Laterally and Torsionally Braced Beams, Journal of Constructional Steel Research, Vol.11, No. 1, pp. 57-68, 1988.

11) Winter, G. : Lateral Bracing of Columns and Beams, Transactions ASCE, Vol. 125, pp.807-845, 1960. 
12) Wang, Y.C. and Nethercot, D. A. : Ultimate Strength Analysis of Three-dimensional Braced I-Beams, Proceedings ICE, pp. 87-112, 1989.

13) Timoshenko, S. P. and Gere, J. M. : Theory of Elastic Stability, 2 nd edition, McGraw-Hill, London, 1961.

14) Adnerson, L. : On the Behaviour of Compression Chords for Through Bridges, Quarterly Journal of Mechanics and Applied Maths, Vol.14, Part 1, pp. 85-100, 1961.

15) Weston, G. : Lateral Buckling in Diaphragm-Braced Beams and Continuous Composite Bridge Girders, Ph. D. Thesis, University of Sheffield, 1987.

16) Hetenyi, M. : Beams on Elastic Foundations, University of Michigan, 1946.

17) Head, P. R. : Private Communication, 1988.

18) Duffield, C. F., Hutchinson, G. L. and Stevens, L. K. : Elastic Torsional Buckling of Through Plate Girder Rail Bridges, Pacific Structural Steel Conference, Auckland, pp. 27-42, 1986.

19) Johnson, R. P. : Limit State Design of Composite Bridges, The Design of Steel Bridges, ed. K. C. Rockey and H. R. Evans, Granada, pp. 243-262, 1981.

20) Nakamura, T. and Wakabayashi, M. : Lateral Buckling of Steel Beams with Reinforced Concrete Slab, Pacific Structural Steel Conference, Auckland, pp. 395-406, 1986.

21) Weston, G. and Nethercot, D. A. : Continuous Composite Bridge Beams-Stability of the Steel Compression Flange in Hogging Bending, Stability of Plate and Shell Structures, ed. P. Dubas and D. Vandepitte, ECCS, pp. 47-52, 1987.

(Received February 8 1989) 